\title{
Qualitative Study on Incorruption of Higher Education
}

\author{
Zhang Yuming \\ Zhuhai Campus, Jinan University, Zhuhai City, China
}

Email address:

112636893@qq.com

To cite this article:

Zhang Yuming. Qualitative Study on Incorruption of Higher Education. Science Journal of Education. Vol. 5, No. 1, 2017 , pp. 19-23. doi: $10.11648 /$ j.sjedu.20170501.14

Received: January 23, 2017; Accepted: February 6, 2017; Published: March 1, 2017

\begin{abstract}
Incorruption in higher education does impose an impact on college students' learning, living and development as well as their cultivation of socialist core values. Based on qualitative study, 80 interviewees are selected in this thesis and materials are collected for coding analysis in the general process of grounded theory. In this way, four aspects of risks on incorruption of higher education are explored from the perspective of impact on the cultivation of socialist core values of college students, namely, damage to the value of equality and justice, violation of incorruption and integrity, violation of civilization and the ruling of law, the breach of work ethics as well as 15 specific risk points for incorruption. Based on that, causes and preventing strategies for incorruption of higher education are put forward by studying of literature works and task analysis.
\end{abstract}

Keywords: Higher Education, Incorruption, College Students, Core Values, Qualitative Studies

\section{Introduction}

College students are in their key period to cultivate their values. As special sub-population of the youth, college students are in their decisive phase where their individual values become stable and finally settle [1]. Therefore, it is of vital importance to proactively provide education of equality, justice and incorruption so as to help them adopt socialist core values and to keep the healthy development of the undertaking of the Party. Meanwhile, as they are mentally immature and their limit in social practice, their values tend to be shallow, unstable, inclusive, contradictory and easy to be influenced by external factors. Under proper external influence, there will be positive effect and vise verse [2]. As a result, incorruption education for college students shall "educate the faculty and students with people and events in the daily life" while "enhancing education of ruling of law as well as incorruption and integrity" [3]. Therefore, it is put forward that although many incorruption events in the daily life of college students are not major or serious cases legally, they do shock honesty education for college students.

According to International Education Research Center, education corruption is defined as "the behavior that systematically takes advantage of public power to seek for individual benefit so that educating opportunities, educational quality and educational equality are imposed serious impact"
[4]. Xie Dan (2012) figures that subjects of higher education corruption include all staff and work institutes; in terms of subjective will of corruption crime includes both behaviors on purpose and negligent behaviors [5]. Combining the studying subject in this thesis, incorruption of higher education in China is put forward as it influences the learning, living and development of college students, and further influences their values on individual and collective malpractice. In fact, it emphasizes the "micro-corruption" in educational functions of higher institutes while general financial corruption which can be seen in all industries (such as infrastructure construction, financial affairs, employee recruitment, etc) is excluded. In this thesis, incorruption in higher education as well as its risk prevention strategies is explored from the perspective of its impact on college students' adoption of socialist core values of equality, justice, ruling of law and integrity.

\section{Methodology}

\subsection{Subjects of Interviewing}

Based on literature work analysis, interviews are given to study opinions and questions of students and staff. In terms of sampling, intensity sampling based on the principle of "targeted sampling" in qualitative study is applied [6]. The interviewees are 60 students from different majors, grades and schools in one university (with 28 from HK, Macao and 
Taiwan included) as well as 20 of the faculty.

\subsection{Studying Tools}

The semi-structured outline of the interview applied in this study is as follows: "Have you ever seen any corruption or injustice in students' daily life? Can you give some examples? What do you think about such corruption or injustice?" The interviews are recorded, written and coded in Word2007 and QSR Nvivo 8.0 (short for N8). N8 is strong in materials packaging and classification, which makes it more systematic and convenient to analyze (Guo Yuxia, 2009) [7].

\subsection{Studying Procedures}

Interviewing: First, an outline of interview should be initially set in accordance with the purpose of this study, and 15 graduating students and 5 of the faculty working over 5 years are interviewed as a test. Based on the test interview, important information shall be founded to analyze notable details as that formal contents and the operation of the interview can be prepared. Second, formal interviews are made among 45 students from different specialties and grades and 15 of the faculty. Each interview is finished within 30 minutes and recorded upon the consent of the interviewees. Interviews received favorable effect as interviewees are informed of the confidentiality.

Content Analysis: Grounded Theory is an iterative researching process. After the record of interviews is rewritten into Word, it is put into N8 to go through gradual abstraction and induction based on three-level coding. First, it goes through open coding in which keywords are taken from the original documents in an open attitude without any theoretical hypothesis to form several "free nodes"; later, by connected coding, these nodes are repeatedly analyzed, classified and inducted to form several categories which are more abstract, namely, "tree nodes"; finally, by core coding, the core type of the document is set based on selective analysis so that its code can be searched and its type connection can be discussed repeatedly to build a theoretical structural model.

\section{Results}

Based on repeated multilevel sorting and coding of the interview materials, it can be found that various incorruption problems in higher education of negative acts and malpractice are common in educational management, teaching management and logistic service. From its impact on college students' adoption of socialist core values, these problems can be classified as 4 risk aspects, namely, damage to the value of equality and justice, violation of incorruption and integrity, violation of civilization and the ruling of law, the breach of work ethics as well as 15 specific risk points for incorruption. The structural model is shown in Picture 1 as follows.

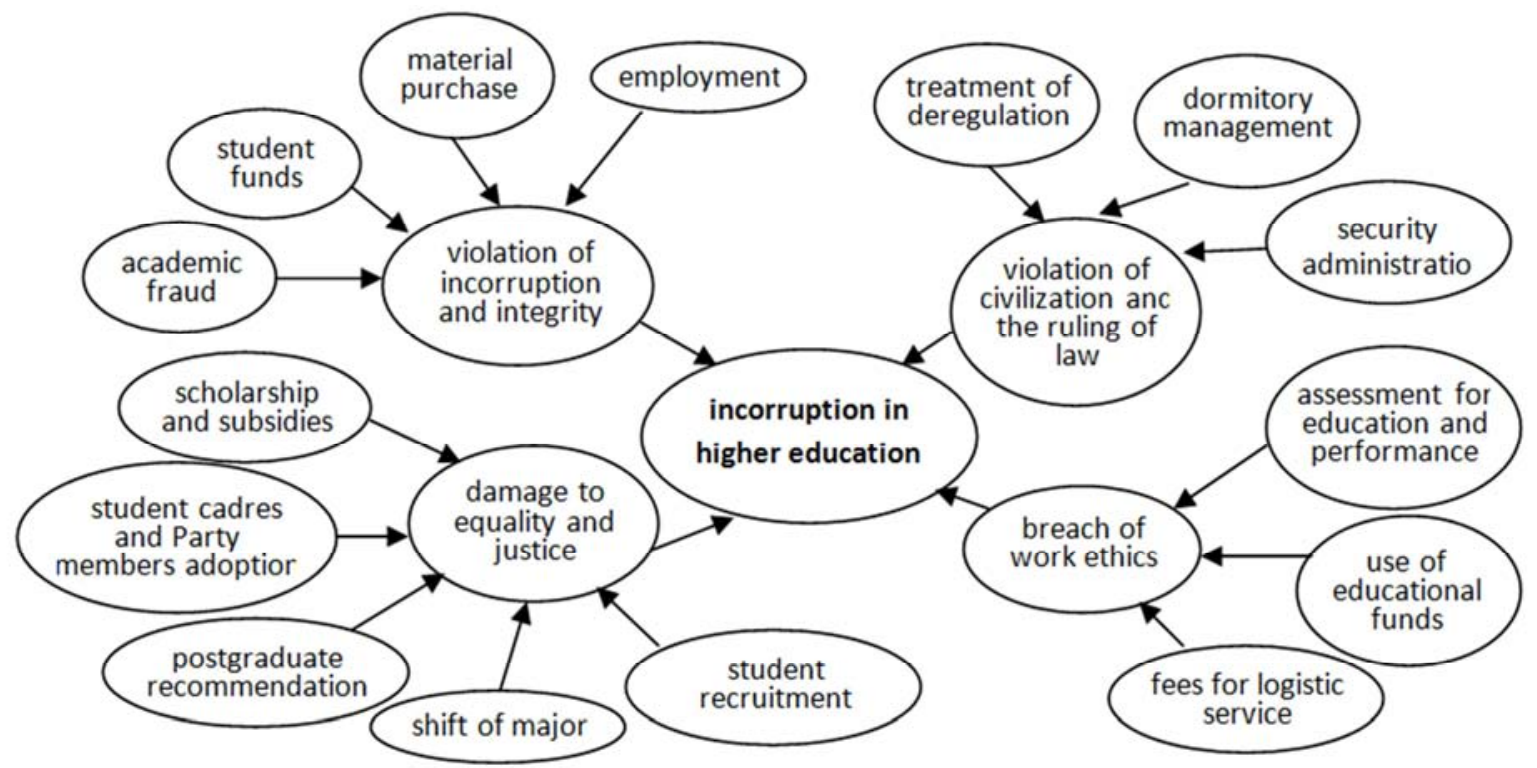

Figure 1. Aspects and Risks of Incorruption in Higher Education.

\subsection{Damage to the Value of Equality and Justice}

(1) Student Recruitment. Programs of Sunshine Recruitment largely enhance the transparency and impartiality, but "there are still some students with privilege recruited through added or adapted rolling enrollment". This is even easier in recruitment of art and sport specialties. As is disclosed by China Youth News, it has been founded in random test that the lowest score of the recruited students in the School of Art in one university was only two, indicating the inside stories of its recruitment [8].

(2) Shift of Specialties. Due to individual interest or job prospect, parents have their expectations of specialties for their children. As a result, "they seek for privilege in all means. Some manage to change the specialties for their children before entering the university, while others shift after one year's study in the university. Some students do not have satisfying performance in their schoolwork but manage to shift their majors into favorable ones without going public". 
(3) Recommendation of Academic Postgraduates. As such recommendation requires academic ability only, there is no specific threshold for recommendation, bringing much space for black box operation. "In assessment of recommended students, the ones whose parents are in good relations with people in charge will have more advantage against those who are equivalently excellent". "In one school, in order to refuse one student who is obviously excellent academically, requires the students to accept the master-doctor continuous study; but the students wishes to hunt a job after graduation as a master, so he has to drop his chance".

(4) Adoption of Party Members and Student Cadres. Although student cadres are involved in the selection of would-be Party members and student cadres, students do not have equal right of speech as their head teachers due to their direct relationship between superior and subordinates. "Some students become probationary Party members by privilege without any training as Party activists". "Student cadres are generally decided by teachers privately and interviews are only pro forma which are neither open nor impartial"; "after the recruitment of some organization, some students are directly recruited by some favorable departments by their good relations with the leaders without election".

(5) Scholarship and Subsidies. "Students that are in good relations with their head teachers have more chances in getting scholarships. Between two students with the same performance, the teacher tends to choose one according to his or her own likes and dislikes, which is not equal"; "the arrangement of subsidies jobs is not equal either, as students in good relations with their teachers can get better jobs, such as jobs in the library".

\subsection{Violation of Incorruption and Integrity}

(1) Academic Fraud. If teachers cheat in academic activities (especially in those students are involved), students' academic ethics will go worse. For example, "under the acquiescence of the supervisor, one student downloads data online and seeks for the mean value of four figures behind the decimal point as his own data and is granted top prize in the competition". "Now it is easy to be permitted for innovative experiment programs, but many students do not use the funds on their program; in fact, they use some other invoice and spend the money. They learn malpractice step by step."

(2) Student Funds. There are also loopholes in funds management for party, league and students activities. For example, "students in some organization go for dinner and have fun overnight and 1000 yuan is paid by unidentified fund"; "Sponsorship for activities is not reported and funds as much as before is applied, so what the sponsorship is used for is unclear". Besides, "it will not be discovered if supervisors make a false report of transportation expenses and office allowances".

(3) Materials Purchase. Textbooks and food for the canteens are purchased by departments in charge of the university, but its purchase procedures are far from open and satisfying. For example, "textbooks are bought in labeled price, so there must be some unjust deals". "Food in our canteen is more expensive than those in canteens of ZD and BS. Although we are told that our university is not earning any money from our food, details of raw materials purchased are never open, so there must be some problems".

(4) Employment. "Students in good relations with their teachers can get several copies of employment agreement to sign with different employers at the same time and choose the best one. This impedes the employment of employers, harms the reputation of the university, occupies the opportunities of other students and imposes negative impact on the employment of younger students". "Some students cheat on their files with the help of teachers".

\subsection{Violation of Civilization and the Ruling of Law}

(1) Treatment of Deregulation. Some cases of deregulation of college students are not treated according to regulations. "Some students of higher grade fought in the basketball match, but were not punished in accordance with regulations; in fact, this case was solved by private negotiation between parents and school leaders. Later, this case was reported, and those teachers and students involved had to be punished".

(2) Dormitory Management. "Management of some dormitories is disorganized as students may change their dorms with acquiescence of teachers or change into better rooms by application". "Some students are never punished for late returning as they are in good relations with the managing staff; they may also bring people from outside and the managing staff will pretend that they do not know about it".

(3) Security Administration. The university does control sellers from outside, but "restaurants that are in good relations with the security safeguards can bring their takeaway food on campus while those have no relation cannot". "once when campus safeguards were expelling booths on campus, the owner of one booth told them that he had paid and was not expelled". "I saw the head of the safeguards beat a short and weak young man in front of the library, and I thought it was uncivilized. But it turned out that the young man just wanted to read books on campus as he lived nearby."

\subsection{The Breach of Work Ethics}

(1) Assessment for Education and Scores. "One student often go out for dinner with teachers and seldom come to class during the entire term, but teachers still allow him to the exams and give him over 80"; "one PE teacher recommends a training class of his friend to his students and promises that those who go to learn in the training class can get added scores in PE exam"; "some teachers require their students to buy the textbook they write at a higher price than those sold online, and threat their students that those who refuse to buy will not pass the exam". "some teachers drop classes due to their personal reasons which damages students' benefit". Besides, "it is hard to mistake students" scores when teachers record students scores in database or when administrators maintain the system".

(2) Use of Educational Funds. Educational funds secure the quality of higher education and the learning benefits of 
students, but it is not rare to abuse those funds. "some schools use educational funds on leisure activities or other meetings without any improvement for education; some teachers spend those funds themselves and report with other invoices".

(3) Fees for Logistic Service. "dormitory administrators often make mistakes when recording our water meter or electric meter, and staff in canteens often charge more than what we should pay. It is hard for us to discover as the figures are small". "when vaccinated, the doctors always tell us that free vaccines are harmful and urge us to get expensive ones". "the maintenance of furniture or water and electricity supply does not have any specification, nor are we given invoice, so we have to pay what the staff charges; besides, the spare parts they replace do not work soon".

\section{Discussion}

\subsection{Reasons of Incorruption Problems in Higher Education}

\section{(1) Change of Values and Driver of Multiple Demands}

With the rapid development of market economy, formal rationality featured by calculability, predictability, supremacy of efficiency and reliance on technology. It involves both taste of consumption and the adoption and improvement of cognition, thinking and values. Under such influence, the values of the literati turn functional, and lead to the declination of culture and the loss of faith [9]. In our real life, the faculty of higher educational institutes have to face their demands and temptation both physically and mentally. For example, the monthly salary of a young teacher is about 5000 yuan, but he or she has to spend 3000 yuan to rent an apartment; besides, he or she has to pay for other expenses in daily life, without much money left for his or her family. Troubled by personal finance, he or she may be extremely eager on festivals, especially when he or she has to go gatherings or visit relatives. Seeing those who take risks in getting unjust money living a better life, they may feel even more depressed and their desire rises. By studying a large number of cases, socialists find that $80 \%$ of criminals commit crimes driven by such mentality of being unfairly treated [10].

(2) Lack of Regulations and Imbalanced Supervision

As was pointed up by Mr. Deng Xiaoping, "mistakes can be attributed to the thoughts and ethics of leaders, but they should be more attribute to organizational and working systems. With effective systems, criminals cannot commit crimes while effective systems, people with ethics cannot do good or even turn criminals" [11]. Although a series of regulations, specifications and systems are set, most of them lack precise and detailed explanations, leading to poor operation but rich "flexibility", largely impacting their force to limit and regulate. In practice, administrative power of a university is always concentrated in hands of top leaders, and such widened administrative power directly limits the playing of academic power. Therefore, hardly can pure educational and academic staff be engaged in decision at various levels (even in academic affairs), so they cannot play as effective limitation for concentrated and widened administrative power. In addition, for the requirement of so-called confidentiality and stability, the vast majority of faculty and students are also isolated outside core information of decision, making it difficult for them to supervision the use of power effectively and in time. For example, the academic committee is not democratic in nature as it is all decided by officials; the faculty and students can only see the modular and centralized y use of funds, so it is hard to supervise.

\subsection{Prevention Strategies for Incorruption Problems in Higher Education}

(1) Incorruption Education Based on Reality Should Be Launched

At present, anti-corruption education has been widely launched among higher institutes through typical cases analysis, meritorious deeds report, anti-corruption center visit, self-reflection exchanges, etc. These activities do have their positive significance, but as one who is educated, the author sees typical features as a political movement. During the period of education, people do reflect and feel touched, but after some time, such reflection and feeling may fade. According to the author, besides the methods above, incorruption and ruling of law should be shown in daily work, so that the vast majority of teachers and students can be better educated by real cases and reflect and restrict themselves in daily cases. For example, democratic concentration is emphasized every day, but it is hardly well-performed in even a small case like student cadre selection: student cadres are elected by voting among students (even freshmen who know no one), or nominated by head teachers, which may be unjust or selfish. There are two solutions: first, the weight of votes can be negotiated before voting; second, members of the class or league cadres can be voted by students and the position of each cadre can be decided collectively. When everyone gets familiar with the democratic and reasonable orders, everyone can be the practitioner and safeguard of incorruption.

(2) Enhance the Power of Regulations in Operation and Restriction

Premier Wen Jiabao figures that the soil of corruption can only be eliminated by system reform [12]. According to Amity, an American scholar, eliminating corruption is just like clearing out rotten apples, as you should not only pick out the rotten one, but only check the apple basket [13]. In order to improve the power in operation and restriction of various regulations, some effective practices in higher institutes abroad can be taken as reference [14]. So far, there are many regulations, but most are extensive with much room for "flexible violation". For example, according to the regulation, educational funds can be spent on education meetings without a clear specification of catering and accommodation threshold or range of participators. Therefore, many people unrelated are invited and the expenses for catering and accommodation are rising from time to time; sometimes, trips may be organized in the name of meetings. Only when existing regulations are dynamically traced and improved confronted with new problems, can restriction in form be enhanced as internal regulations. 
People have different motivations in playing personal rights and public powers. Personal rights are always safeguarded while public powers might be rent-seeking. Just as was said by Montesquieu, the French thinker, "one with power may easily abuse his power until there is a boundary; this is a forever truth" [15]. Based on the disclosed cases of discipline-violation and law-breach in higher institutes so far, one important commonness is that the decision of major events for the leaders lacks powerful supervision [16]. To solve this problem, the rules of decision-making such as general meeting of shareholders, board of directors and board of supervisors in a corporation can be taken as reference to build effective decision-making procedures featuring congress of teacher representatives, meetings of the Party commission and expert panel to achieve the democratic check and balance in university governance.

(3) Independent and Open Supervising System Should Be Built

Regulations are always behind the changes of things compared with the subjectivity of humans (although sophisticated and insightful regulation-builders are able to make them advanced in some certain period). Therefore, effective supervision on use of power is beneficial and effective. At present, supervision from upper leaders is out of reach, supervision from lower level is too risky, supervision from the equivalent level is too difficult, supervision from discipline-inspection staff is not powerful enough, supervision from the organization is not long-effective while supervision by law is too late in higher institutes. External supervision, however, is rare, not concentrated and late, so hardly can it be effective and in time. Therefore, it is necessary that discipline-inspection department be independent and work directly under the leadership of upper-level or municipal discipline-inspection commissions; besides, all expenses and decisions should be open effectively. As members of the academic joint, the position of teachers and students in higher institutes should be fully respected and their ability to tell the truth from fact should be trusted. For example, to recommend postgraduates, student representatives can be randomly selected to be engaged in the discussion of the panel from the beginning to the end, and the materials of all candidates as well as the decisions of all judges (reasons included) should go public online. In this way, no one dare to abuse his or her power in the age of "we media". Premier Li Keqiang once said that power should be used openly and transparently, so that people can fully and effectively supervise the power to be used for the benefit of the public instead of personal interests [17]. It is proved by Chowdhury (2004) based on case study that democracy and freedom of speech obviously restrain corruption [18].

\section{Acknowledgments}

This study is a phase result of the Educational Research of Politics of College Students in HK, Macao and Taiwan with Excellent Traditional Chinese Culture Integrated
(14JDSZ2013) in the Special Program of Cultural and Social Science Studies (on Politics of Higher Institutes) of the Ministry of Education in 2014.

\section{References}

[1] Huang Xiting, Xu Fengshu. Psychology of College Students. Shanghai: Shanghai People's Press, 1988: 212.

[2] Ye Songqing. Status and Features of Values of Contemporary College Students. Exploration of the Youth, 1996 (01): 32.

[3] Ministry of Education. Guidance on Comprehensive Education of Incorruption in Primary Schools, Middle Schools and Higher Institutes by the Ministry of Education. 2007-3-27.

[4] Zhang Jiayong et al. International Challenges: Types, Roots and Strategies of Education Corruption. Contemporary Educational Forum, 2007 (8): 22.

[5] Xie Dan. Study on Designing of Anti-corruption Systems in Higher Institutes. Southwest University, 2012: 3.

[6] Wu Jixia, Huang Xiting. On Structure of Integrity. Journal for Psychology, 2012 (3): 356.

[7] Guo Yuxia. Analysis to Materials of Qualitative Study: Instructions to the Use of Nvivo 8. Taipei: Higher Education, 2009 (7): 40-42.

[8] Qiao Hua et al. Disclosure on Blackbox Cases in Student Recruitment in School of Art of Hainan University. China Youth News, Page 5 of August $5^{\text {th }}, 2003$.

[9] Wang Weizhong. Study on Corruption of Higher Education and Development of Honesty. Southwest University, 2011: 55.

[10] Dong Yan. On Reasons of Corruption among Officials in Higher Institutes and Strategies for Anti-corruption in the New Period. Northeast Normal University, 2007: 13.

[11] Deng Xiaoping. Selected Works of Deng Xiaoping. Beijing: People's Press, 1988: 185.

[12] Hao Hong. Corruption Causes the Peoples's Dissatisfaction and Anti-corruption Is to the Will of the People. Beijing Times, 2011 (3): 16.

[13] Liu Jingmei. Study on Prevention and Control of Duty-related Crimes in Higher Institutes. Sichuan People's Press, 2009: 253.

[14] Wang Weizhong. Study on Corruption in Higher Institutes and the Development of Honesty. Southwest University, 2011: 69-88.

[15] Montesquieu. The Spirit of Law (I). Commercial Press, 1982: 12.

[16] Lin Jiankun. On the Power Restriction of Logistics and the Development of Anti-corruption Systems. Shanghai: East China Normal University, 2010: 1.

[17] http://finance.ifeng.com/news/special/2013lianghui/20130318/ 7784595.shtml.

[18] Chowdhury, S. K., 2004. The Effect of Democracy and Press Freedom on Corruption: An Empirical Test. Economic Letters, 85 (1), 93-101. 